Jurnal Sistim Informasi dan Teknologi
https://jsisfotek.org/index .php

\title{
Sistem Pakar Menggunakan Metode Backward Chaining dalam Mengidentifikasi Kandungan Senyawa Boraks, Formalin, Rhodamin B dan Metanil Yellow pada Makanan
}

\author{
Muhammad Irvan Kholi1 ${ }^{1 凶}$, Gunadi Widi Nurcahyo ${ }^{2}$ \\ ${ }^{1,2}$ Universitas Putra Indonesia YPTK Padang \\ irv.kho1i1@gmai1.com
}

\begin{abstract}
This research is motivated by the increasing number of food producers using additives that are not permitted to be used or which are harmful to health. The addition of hazardous substances in food and beverages has a huge effect on health. The use of these dangerous substances can cause inflammation of the digestive tract, degeneration or wasting of the liver, odema / swelling of the brain, accumulation of fluid in the organs of the body. This analysis applies the Backward Chaining Method in the Expert System, namely by the system processing existing facts to lead to conclusions. Facts are obtained from physical conditions, also known as symptoms. Backward Chaining is goal-driven reasoning, which begins with making predictions of what will happen, then looking for evidence that supports (or refutes) the hypothesis. In the Expert System for identifying chemical compounds of borax, formalin, rhodamine b and methanyl yellow in food using the Backward Chaining Method, the results obtained from the expert's matching data with the results of which results matched 6 out of 6 data, or with a percentage of $100 \%$. The resulting solution is that the sample must be tested for labor. It is hoped that this application can help the public in educating chemical compounds in food and identifying the initial stages of food before being reported to the Food and Drug Supervisory Agency for laboratory testing.
\end{abstract}

Keywords: Borax, Formalin, Rhodamine B, Methanyl Yellow, Backward Chaining.

\begin{abstract}
Abstrak
Penelitian ini dilatarbelakangi oleh maraknya produsen pangan yang menggunakan bahan tambahan yang tidak diizinkan penggunaannya atau berbahaya bagi kesehatan. Penambahan bahan berbahaya dalam makanan minuman mempunyai pengaruh yang sangat besar terhadap kesehatan. Penggunaan bahan berbahaya ini dapat menimbulkan radang pada saluran pencernaan, degenerasi atau pengecilan hati, Odema/pembengkakan pada otak, penimbunan cairan pada organ tubuh. Analisis ini menenerapkan Metode Backward Chaining dalam Sistem Pakar yaitu dengan cara sistem memproses fakta yang ada untuk mengarah pada kesimpulan. Fakta diperoleh dari kondisi fisik, atau disebut sebagai gejala. Backward Chaining adalah penalaran berdasarkan tujuan (goal-driven), yang dimulai dengan membuat perkiraan dari apa yang akan terjadi, kemudian mencari fakta-fakta (evidence) yang mendukung (atau membantah) hipotesa tersebut. Pada Sistem Pakar identifikasi senyawa kimia boraks, formalin, rodamin b dan metanil yellow pada makanan menggunakan Metode Backward Chaining didapatlah hasil kecocokan data dari pakar dengan hasil pencarian tersebut mendapatkan kecocokan 6 dari 6 data, atau dengan persentase $100 \%$. Solusi yang dihasilkan yaitu sampel tersebut harus dilakukan pengujian labor. Diharapkan aplikasi ini dapat membantu masyarakat dalam edukasi senyawa kima pada makanan dan mengidentifikasi tahap awal makanan sebelum dilaporkan ke Pengawas Obat dan Makanan untuk dilakukan pengujian labor.
\end{abstract}

Kata kunci: Boraks, Formalin, Rodamin B, Metanil Yellow, Backward Chaining.

(C) 2021 JSisfotek

\section{Pendahuluan}

Sistem Pakar pertama kali dikembangkan pada tahun 1960 dan 1970 dan diterapkan secara komersial pada tahun 1980. Sistem Pakar adalah sistem berbasis komputer yang menggunakan pengetahuan, fakta, dan Konsep dasar Sistem Pakar adalah keahlian yang teknik penalaran dalam memecahkan masalah yang ditransfer ke komputer, keahlian yang terdiri dari biasanya hanya dapat dipecahkan oleh seorang pakar pengetahuan yang disimpan dan digunakan oleh system dalam bidang tertentu. Sistem Pakar memberikan nilai untuk mencari solusi dari fakta-fakta yang didapat. tambah pada teknologi untuk membantu dalam Tujuan utama dari sistem pakar bukan mengantikan menangani era informasi yang semakin canggih [1]. peran seorang pakar atau seorang ahli, tetapi lebih Sistem Pakar merupakan sistem berbasis komputer sebagai jembatan antara seorang pakar dengan yang menggunakan pengetahuan, fakta dan teknik pengguna yang membutuhkan pengetahuan dibidang penalaran dalam memecahkan masalah yang biasanya kepakaran tersebut. Disisi lain Sistem Pakar dapat hanya dapat dipecahkan oleh seorang pakar dalam menjadi asisten seorang pakar yang dapat membantu

bidang tersebut. Dengan adanya Sistem Pakar masyarakat mampu menyelesaikan permasalahan yang sebenarnya hanya bisa diselesaikan dan dikerjakan dengan bantuan para pakar di bidang tertentu [2].

Diterima: 07-10-2020 | Revisi: 21-10-2020 | Diterbitkan: 31-03-2021 | DOI: 10.37034/jsisfotek.v3i1.41 
kinerja seorang pakar [3]. Backward Chaining adalah adalah 95\% akurat. Maka Sistem Pakar berbasis Penalaran berdasarkan tujuan (goal-driven), metode ini Android dapat menjadi alternatif awal dalam dimulai dengan membuat perkiraan dari apa yang akan melakukan identifikasi penyakit jamur kulit pada terjadi, kemudian mencari fakta-fakta (evidence) yang manusia [10]. mendukung (atau membantah) hipotesa tersebut. Backward Chaining adalah suatu alasan yang berkebalikan dengan hypothesis, potensial konklusinya mungkin akan terjadi atau terbukti, karena adanya fakta yang mendukung akan hypothesis tersebut. Dengan kata lain, prosesnya dimulai dari initial hyphotesis or goal (Hipotesa awal atau tujuan) melalui intermediet hypotheses or sub goals (hipotesa lanjutan atau bagian dari tujuan) yang akan memeriksa semua hipotesa yang ada apakah hipotesa itu benar atau salah sehingga akhirnya akan menuju suatu fakta [4].

Sebuah mesin inferensi menggunakan Backward Chaining akan mencari aturan inferensi sampai menemukan satu yang memiliki konsekuensi (Kemudian klausa) yang cocok dengan tujuan yang diinginkan. Jika yg (jika klausa) dari aturan yang tidak diketahui benar, maka itu akan ditambahkan ke daftar tujuan (agar tujuan seseorang untuk dikukuhkan satu juga harus memberikan data yang menegaskan aturan baru ini). Sering hal ini memerlukan perumusan dan pengujian hipotesis sementara. Pada metode inferensi dengan Backward Chaining akan mencari aturan atau rule yang memiliki konsekuen (Then klausa..) yang mengarah kepada tujuan yang di skenariokan / di inginkan [5]. Metode Backward Chaining ini bisa Adapaun kerangkan kerja penelitian dapat dilihat pada digunakan pada Diagnosa Terjadinya Waste Plastik Gambar 1.

dimana dapat mengetahui kendala - kendala yang sering terjadi dan dapat diatasi [6].

Penerapan Backward Chaining yang lainnya terdapat pada bidang kesehatan seperti mendeteksi penyakit berdasarkan golongan darah berbasis android yang untuk mendapatkan informasi mengenai jenis penyakit yang diderita berdasarkan golongan darah [7]. Selain itu juga diterapkan untuk mendiagmosa penyakit tulang. hasilnya dapat digunakan untuk membantu masyarakat untuk mengenali atau mendiagnosa awal penyakit tulang secara dini [8]. Aplikasi sistem pakar yang menerapkan rule-rule pada Backward Chaining menghasilkan inferensi dan reasoning serta penjelasannya dapat menyelesaikan permasalahan sangketa tanah. Kasus sangketa tanah dengan pendekatan menginputkan penyebab kasus sangketa tanah kemudian program akan melakukan penghitungan nilai probabilitas. Nilai probabilitas tertinggi-lah yang nantinya akan diambil. Rule yang memiliki konsekuen untuk menampilkan hasil solusi dengan cepat dan tepat [9].

Sistem pakar berbasis Android untuk mengidentifikasi jenis penyakit dan nilai keyakinan terhadap penyakit jamur kulit pada manusia. Sistem Pakar dapat memberikan informasi tentang penyakit dan solusi penyakit jamur kulit pada manusia. Berdasarkan pengujian sistem yang dilakukan dengan 20 data uji dan membandingkan hasil yang didapat oleh istem dengan pendapat dokter diperoleh hasil dari sistem

\section{Metodologi Penelitian}

Pada BAB ini menjelaskan beberapa tahap yang akan dilakukan untuk dapat mengatasi permasalahan yang ada. Tahapan ini merupakan gambaran umum dari penelitian yang akan dilakukan. Penelitian adalah cara yang sistematis untuk menjawab suatu masalah yang akan diteliti menggunakan metode ilmiah melalui tahapan yang terstruktur dan keteraturan. Metode sangat diperlukan dalam membuat penulisan supaya dapat terarah dengan baik. Tujuan dari penelitian ini untuk memberikan informasi kepada masyarakat supaya bisa mengidentifikasi tahap awal kandungan senyawa kimia berbahaya pada makanan. Data yang dibutuhkan dalam penelitian ini berupa fakta-fakta yang digunakan oleh pakar dalam mengidentifikasi kandungan senyawa kimia berbahaya pada makanan. Selanjutnya data-data tersebut dijadikan sebagai rule untuk mengetahi terdapat atau tidak nya kandungan kimia pada makanan dengan menggunakan metode Backward Chaining sebelum diteliti di laboratorium.

Semua penelitian ini dituangkan di kerangka kerja penelitian yang merupakan langkah-langkah yang akan dilakukan dalam penyelesaian masalah yang dibahas.

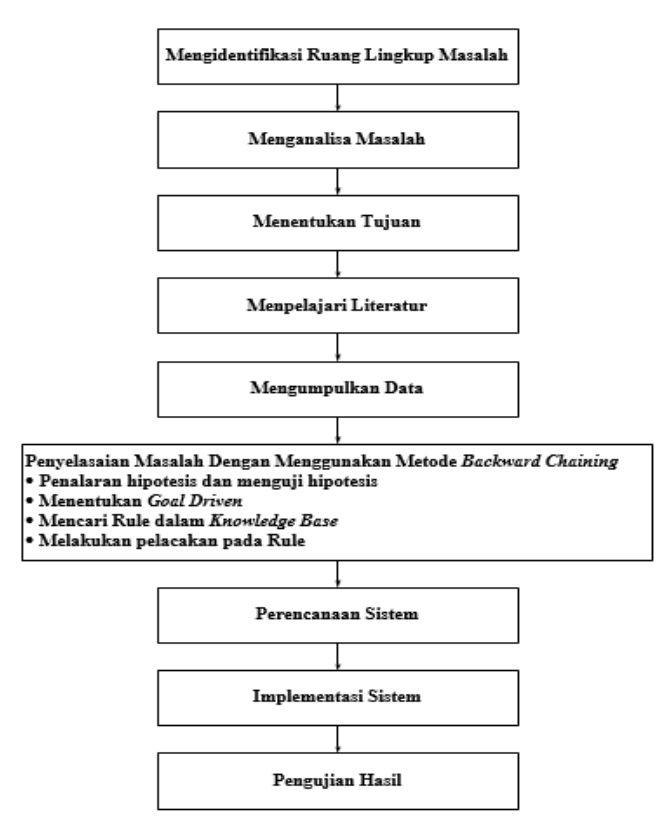

Gambar 1 Kerangka Kerja Penelitian

Berdasarkan kerangka kerja pada Gambar 1, maka masing-masing tahapannya dapat dijelaskan pada sub bagian berikut.

Jurnal Sistim Informasi dan Teknologi Vol.3 No. 1 (2021) 34-40 


\subsection{Mengidentifikasi Ruang Lingkup Masalah}

Ruang lingkup masalah yang akan diteliti harus ditentukan terlebih dahulu, agar mampu menjelaskan dan menentukan ruang lingkup yang akan diteliti. Jadi mendeskripsikan ruang lingkup masalah ini merupakan langkah awal dalam melakukan penulisan ini.

\subsection{Menganalisa Masalah}

Menganalisa permasalahan merupakan alur berikutnya agar penelitian yang akan dilakukan dapat memahami masalah yang telah ditentukan batasan masalahnya. Diharapkan dengan masalah yang telah ditentukan dapat menganlisa tersebut dengan baik.

\subsection{Menentukan Tujuan}

Tujuan penelitian adalah suatu hal yang akan dicapai pemrograman PHP yang menerapkan Metode dalam suatu penelitian yang dilakukan. Tujuan membandingkan hasil yang didapatkan dengan analisa penelitian merupakan hasil akhir yang diharapkan secara manual dengan sistem. Dalam membangun tercapai setelah penelitian tersebut dilakukan. Tujuan sebuah sistem yang berbasis komputerisasi ada 2 penelitian harus ditentukan diawal terlebih dahulu komponen yang harus dipenuhi, yaitu spesifikasi sebelum penelitian dilakukan. Menentukan tujuan hardware dan software yang. penelitian sangat diperlukan agar penelitian yang dilakukan bermanfaat bagi penggunanya.

\subsection{Mempelajari Literatur} maka dipelajari literatur- menggunakan Metode Backward Chaining. Hasil literatur yang dibutuhkan. Kemudian literatur-literatur tersebut akan dibandingkan dengan data-data riil yang yang dipelajari tersebut diseleksi dan dipilih literatur ada untuk melihat tingkat persentase (\%) mana yang akan digunakan dalam penelitian. Literatur keakuratannya.

diambil dari berbagai sumber yaitu berupa artikel, jurnal ilmiah tentang Sistem Pakar Metode Backward Chaining, serta bahan bacaan lain yang mendukung.

\subsection{Mengumpulkan Data}

Mengumpulkan data dilakukan untuk dapat memperoleh informasi data-data yang dibutuhkan dalam penelitian rangka mencapai tujuan penelitian. Data yang digunakan dalam penelitian ini merupakan Pada metode penelitian ini peneliti menggunakan data yang diambil dari seorang pakar. Data yang beberapa metode penelitian dalam pengumpulan data, diperoleh melalui wawancara dan studi literatur yaitu Field Research dan teknik kalkulasi. Field perpustakaan. Referensi yang digunakan berupa buku Reseach merupakan sebuah metode penelitian agar dan jurnal yang disarankan oleh pakar. Data ini dapat menghasilkan data yang optimal, maka diperoleh secara formal oleh peneliti yaitu dengan diperlukan penilitian lapangan, di mana penelitian menyerahkan surat izin meneliti. Selanjutnya dilakukan lapangan ini melakukan pengambilan data secara kegiatan penelitian bersama pakar untuk memperoleh langsung. Teknik kalkulasi adalah menghitung data data. Data mengenai ciri fisik makanan yang yang tersedia untuk menghasilkan informasi yang mengandung senyawa kimia Boraks, Formalin, berguna di dalam penelitian ini.

\subsection{Penyelesaian Masalah dengan Menggunakan Metode Backward Chaining}

Agar permasalahan penelitian ini mendapatkan solusi maka dilakukan analisa dan perancangan terhadap pac permasalahan yang ada berdasarkan data-data yang telah dikumpulkan dengan tahapan-tahapan yang ada kin dalam Metode Backward Chaining.

Rodamin B, dan Metanil Yellow didapat dari hasil wawancara dengan pimpinan Loka POM Dharmasraya. Sumber data juga diperoleh dari berbagai buku yang berkaitan dengan senyawa kimia serta pencarian sumber data dari Internet. Objek yang akan dibahas pada penelitian ini adalah tentang ciri - ciri fisik yang terdapat pada makanan yang mengandung senyawa kimia. Penjelasan mengenai Jenis senyawa kimia tersebut dapat dilihat pada Tabel 1 .

\subsection{Perancangan Sistem}

Merancang sistem merupakan rancangan awal sebelum sistem itu digunakan. Hasil dari tahapan ini nantinya 
Muhammad Irvan Kholil, Gunadi Widi Nurcahyo.

Tabel 1 Jenis - jenis Senyawa Kimia Pada Makanan

\begin{tabular}{cl}
\hline $\begin{array}{c}\text { Kode } \\
\text { Kandungan }\end{array}$ & Jenis Senyawa Kimia Pada Makanan \\
\hline K1 & Kandungan Senyawa Boraks \\
K2 & Kandungan Senyawa Formalin \\
K3 & Kandungan Senyawa Rhodamin B \\
K4 & Kandungan Senyawa Methanil Yellow \\
\hline
\end{tabular}

Ciri ciri fisik makanan yang mengandung senyawa kimia akan dijelaskan pada Tabel 2.

Tabel 2 Ciri - ciri Senyawa Kimia Pada Makanan

\begin{tabular}{cl}
\hline Kode & Ciri - ciri Makanan Yang Mengandung Zat Kimia \\
\hline C1 & Bertekstur Kenyal \\
C2 & Tidak Mudah Lengket \\
C3 & Berwarna Mencolok \\
C4 & Beraroma Mencurigakan, Binatang tidak mau \\
& mendekat \\
C5 & Tidak Rusak atau Busuk Meski Disimpan 3 Hari \\
& diluar lemari Pendingin \\
C6 & Tidak Rusak atau Busuk Meski Disimpan 15 Hari \\
& didalam Lemari Pendingin \\
C7 & Tercium Bau Menyengat Pada Makanan \\
C8 & Mi Berwarna Mengkilap, Tidak Lengket, dan Tidak \\
& Mudah Putus \\
C9 & Tahu Bertekstur Lebih Keras dan Kenyal \\
C10 & Ayam Bertekstur Padat dan Lebih Keras Dibanding \\
& Ayam Pada Umumnya \\
C11 & Ikan Segar memiliki Warna Insang Merah Tua \\
C12 & Daging Berwarna Putih Pucat \\
C13 & Makanan Berwarna Merah Cerah dan Lebih \\
C14 & Mencolok \\
& Warna Tidak Merata, Terlihat Gumpalan Warna Pada \\
C15 & Makanan \\
C16 & Makanan Terasa Lebih Pahit \\
C17 & Wetelah Dimakan Terasa gatal Di Tenggorokan \\
& Meninggalkan Bekas Warna \\
&
\end{tabular}

\subsection{Data}

Berikut adalah data yang didapatkan dari Loka POM Dharmasraya, di mana data yang ditampilkan merupakan data yang terdapat di Loka POM tersebut. Seperti yang terlihat pada Tabel 3.

Tabel 3 Data Yang Diperoleh Dari Pakar

\begin{tabular}{|c|c|c|c|}
\hline No & $\begin{array}{l}\text { Nama } \\
\text { Makanan }\end{array}$ & Ciri - ciri Fisik Makanan & Hasil Uji \\
\hline \multirow[t]{7}{*}{1} & $\begin{array}{l}\text { Delima } \\
\text { (Bahan }\end{array}$ & -Bertekstur Kenyal & Boraks \\
\hline & Cendol) & -Tidak Mudah Lengket & \\
\hline & & -Tidak Rusak atau Busuk Meski & \\
\hline & & Disimpan 3 Hari diluar lemari & \\
\hline & & Pendingin & \\
\hline & & -Tercium Bau Menyengat & \\
\hline & & -Makanan Berwarna Merah dan & \\
\hline \multirow{13}{*}{2} & Mie & $\begin{array}{l}\text { Lebih Mencolok } \\
\text {-Bertekstur Kenyal }\end{array}$ & Boraks \\
\hline & & -Tidak Mudah Lengket & \\
\hline & & -Warna Kuning Mencolok & \\
\hline & & -Mi Berwarna Mengkilap, Tidak & \\
\hline & & Lengket, dan Tidak Mudah & \\
\hline & & Putus & \\
\hline & & -Tidak Rusak atau Busuk Meski & \\
\hline & & Disimpan 3 Hari diluar lemari & \\
\hline & & Pendingin & \\
\hline & & -Beraroma Mencurigakan, & \\
\hline & & Binatang tidak mau mendekat & \\
\hline & & -Tidak Rusak atau Busuk Meski & \\
\hline & Ikan & Disimpan 15 Hari didalam & \\
\hline 3 & Tongkol & Lemari Pendingin & Formalin \\
\hline
\end{tabular}

-Beraroma Mencurigakan,

Binatang tidak mau mendekat

-Ikan Segar memiliki Warna

Insang Merah Tua

-Daging Berwarna Putih Pucat

-Tidak Rusak atau Busuk Meski

Disimpan 15 Hari didalam

Lemari Pendingin

-Tercium Bau Menyengat Pada

Formalin

Potong

Makanan

- Ayam Bertekstur Padat dan

Lebih Keras Dibanding Ayam

Pada Umumnya

-Daging Berwarna Putih Pucat

Kerupuk

Merah

-Berwarna Mencolok

-Warna Tidak Merata, Terlihat

Gumpalan Warna Pada

Makanan

-Makanan Terasa Lebih Pahit

-Meninggalkan Bekas Warna

- Warna Tidak Merata, Terlihat

Agar - agar Gumpalan Warna Pada

6 Es Campur Makanan

-Setelah Dimakan Terasa Gatal

Di Tenggorokan

- Warna Kuning Mencolok

-Meninggalkan Bekas Warna

Rodamin B

Metanil

Yellow

\subsection{Rule}

Dari data senyawa kimia, ciri - ciri senyawa kimia tersebut dan data riil yang diperoleh Dari Loka POM makan didapat rule seperti yang terlihat pada Tabel 4 berikut.

Tabel 4 Rule Atau Aturan Yang Diproleh

\begin{tabular}{|c|c|}
\hline Kode & Aturan (rule) \\
\hline L1 & $\begin{array}{l}\text { IF C1=Benar, AND C2=Benar, AND C3=Benar, AND } \\
\text { C4=Benar, AND C5=Benar Then }\end{array}$ \\
\hline L2 & IF C13=Benar Then C3 \\
\hline L3 & IF C17=Benar Then C3 \\
\hline L4 & IF C7=Benar Then C4 \\
\hline L5 & $\begin{array}{l}\text { IF C } 5=\text { Benar, AND C6 }=\text { Benar, AND C } 7=\text { Benar, AND } \\
\text { C } 8 \text { Then K } 2\end{array}$ \\
\hline L6 & $\begin{array}{l}\text { IF C5= Benar, AND C6=Benar, AND C7=Benar, AND } \\
\text { C9=Benar Then K2 }\end{array}$ \\
\hline L7 & $\begin{array}{l}\text { IF C } 5=\text { Benar, AND C } 6=\text { Benar, AND C } 7=\text { Benar, AND } \\
\text { C } 10=\text { Benar, AND C } 12=\text { Benar Then K } 2\end{array}$ \\
\hline L8 & $\begin{array}{l}\text { IF C5= Benar, AND C6 }=\text { Benar, AND C } 7=\text { Benar, AND } \\
\text { C } 11=\text { Benar, AND C } 12=\text { Benar Then K } 2\end{array}$ \\
\hline L9 & IF C4=Benar Then C7 \\
\hline L10 & IF C6=Benar Then C5 \\
\hline L11 & $\begin{array}{l}\text { IF C13=Benar, AND C14=Benar, AND C15=Benar, } \\
\text { AND C18=Benar Then K3 }\end{array}$ \\
\hline L12 & IF C3=Benar Then C13 \\
\hline L13 & $\begin{array}{l}\text { IF C14=Benar, AND C16=Benar, AND C } 17=\text { Benar, } \\
\text { AND C18=Benar Then K } 4\end{array}$ \\
\hline L14 & IF C3=Benar Then C17 \\
\hline
\end{tabular}

\subsection{Proses Pencarian}

Proses pencarian dilakukan berdasarkan data dari hasil konsultasi warga dengan pakar untuk memastikan makanan yang dicurigai oleh warga warga tersebut benar mengandung senyawa kimia Boraks. Berdaserkan hasil wawancara tersebut terdapat ciri ciri makanan yang dicurigai oleh warga tersebut, di mana ciri - ciri tersebut akan dieksekusi menggunakan Metode Backward Chaining untuk memastikan 
kandungan senyawa kimia Boras (K1) dengan ciri - ciri diketahu bahwa fakta C13 terpenuhi, makan Goal C3 $\mathrm{C} 1, \mathrm{C} 2, \mathrm{C} 5, \mathrm{C} 7, \mathrm{C} 13$ berikut proses pencarian nya:

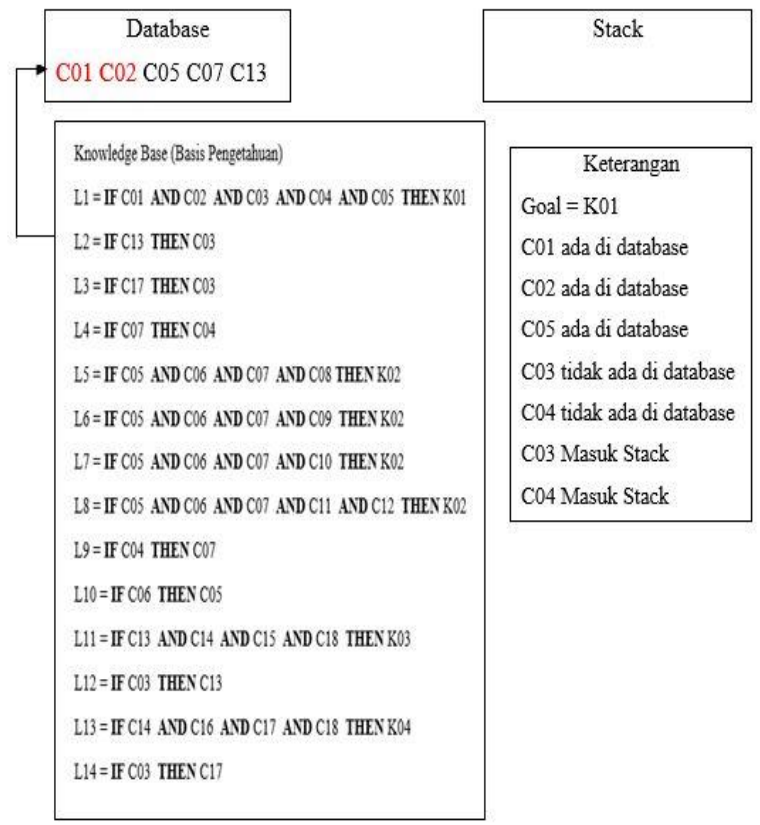

Gambar 2. Proses Iterasi Pertama

Pada proses iterasi pertama diketahui Goal yang akan dituju adalah K1 di mana untuk mencapai Goal tersebut berdasarkan Knowledge Base yang ada maka rule yang harus dipenuhi adalah C1, C2, C3, C4, C5. Pada fakta hasil wawncara diketahui bahwa fakta yang ada hanya Pada iterasi ke 3 Goal yang akan akan dicapai adalah C1, C2, C5, C7, C13 karena fakta C3 dan C4 belum C4, di mana untuk mencapai Goal C4 fakta yang harus terpenuhi maka fakta C3 dan C4 dimasukkan ke dalam terpenuhi adalah C7. Dikethui di Database terdapat Stack.

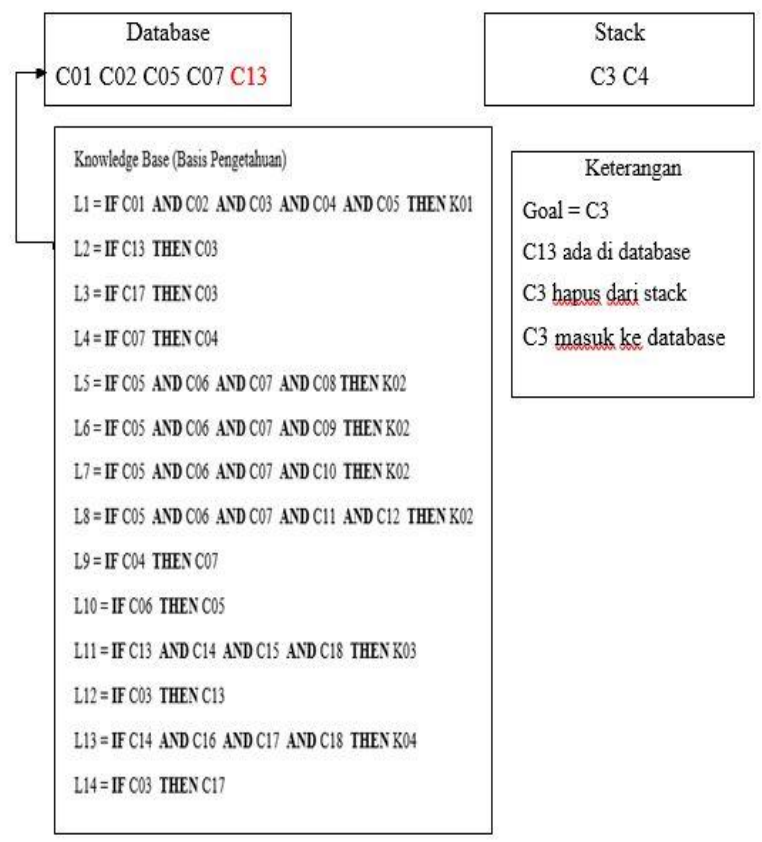

\section{Gambar 3. Iterasi Ke Dua Goal}

Pada iterasi ke 2 Goal yang akan dicari adalah C3, berdasarkan Knowledge Base untuk mendapatkan Goal tersebut harus ada fakta C13 atau C17. Pada Database didapatkan, dan fakta C3 dihapus dari Stack dan C3 menjadi fakta baru.

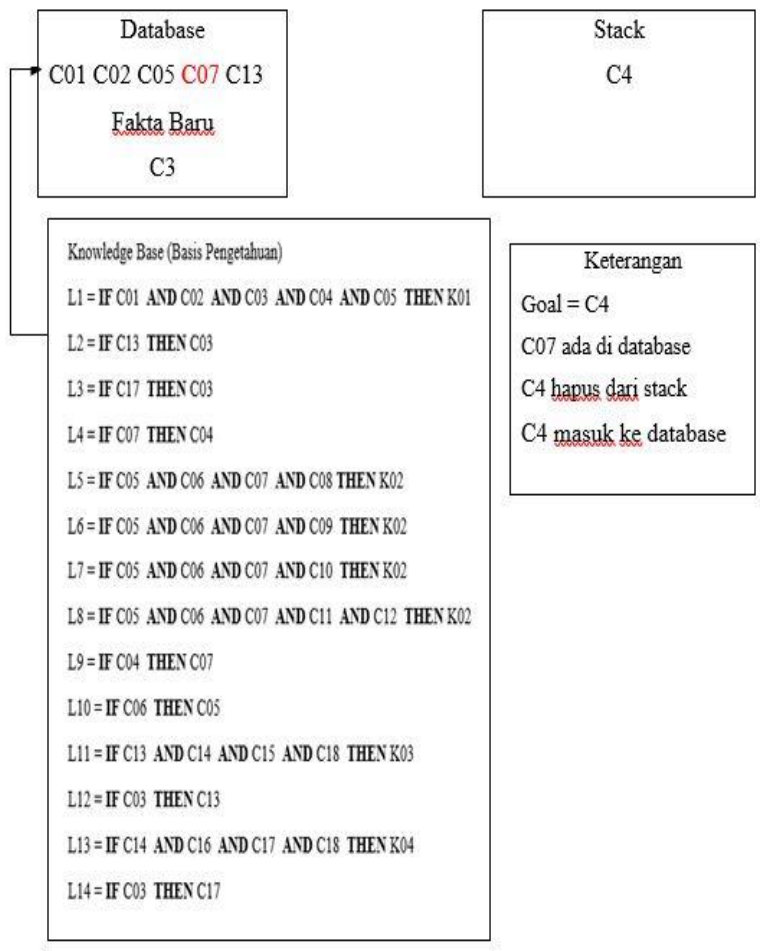

Gambar 4. Iterasi ke Tiga Goal fakta C7, makan rule untuk mendapatkan Goal C4 terpenuhi. Maka fakta C4 dihapus dari Stack dan fakta C4 menjadi fakta baru.

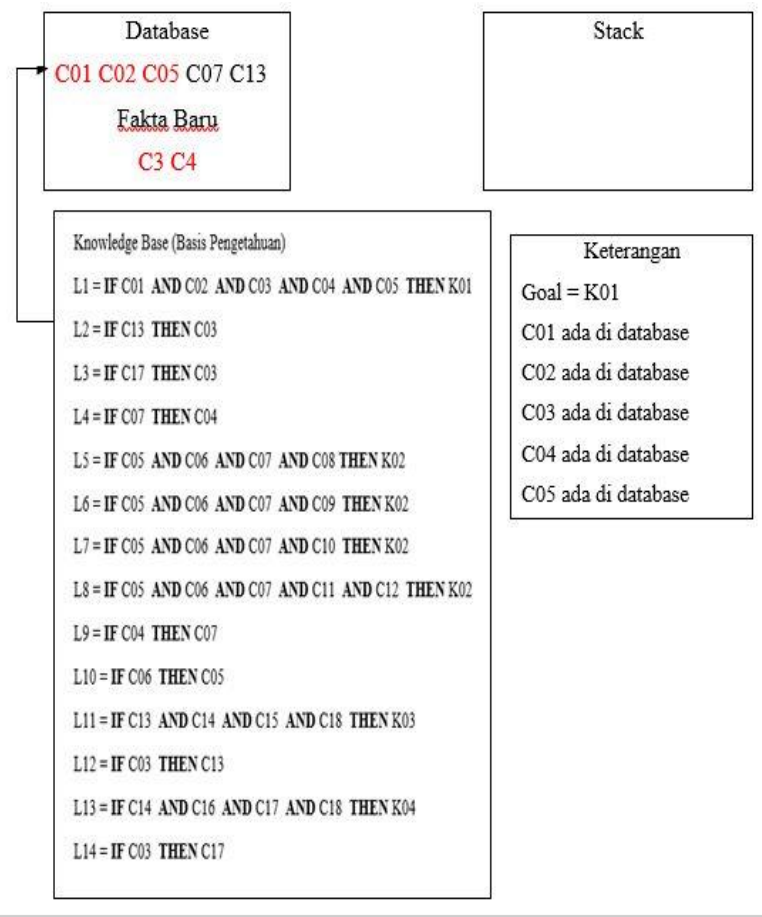

Gambar 5. Goal K1

Jurnal Sistim Informasi dan Teknologi Vol.3 No. 1 (2021) 34-40 
Karena Goal K1 ditemukan di Database, maka proses pencarian dihentikan. Berdasarkan hasil pencarian iterasi diketahui bahwa fakta C1, C2, C5, C7, C13 tersebut makanan tersebut teridentifikasi mengandung senyawa Boraks dan layak untuk diuji lebih lanjut di labor.

\subsection{Hasil}

Pengujian terhadap beberapa data makanan dilakukan untuk melihat seberapa besar tingkat akurasi hasil Sistem Pakar dengan hasil yang diberikan pakar. Dalam pengujian ini yang menjadi hasil pengujian adalah nama senyawa kimia dan ciri - ciri fisik makanan dan hasil nya dibandingkan secara langsung pada Sistem Pakar.

Sistem penilaian keakuratan system terdiri dari 2 level, yaitu level 0 dan level 1 . Level 0 diberikan jika hasil diagnose system tidak samadengan hasil diagnose pakar dan level 1 diberikan jika diagnose sistem dan pakar memberikan hasil yang sama. Adapun hasil pengujian sistem dengan beberapa data pasien beserta perbandingannya dengan keputusan pakar dapat dilihat pada Tabel 5.

Tabel 5 Hasil Dari Pengujian Data Riil

\begin{tabular}{|c|c|c|c|c|c|}
\hline No & $\begin{array}{l}\text { Nama } \\
\text { Makanan }\end{array}$ & Ciri - ciri Fisik Makanan & Hasil Uji & Akurasi & $\begin{array}{l}\text { senyawa kima pada makanan dan mengidentifikasi } \\
\text { tahap awal makanan sebelum dilaporkan ke Pengawas }\end{array}$ \\
\hline \multirow[t]{2}{*}{1} & $\begin{array}{l}\text { Delima } \\
\text { (Bahan }\end{array}$ & -Bertekstur Kenyal & Boraks & 1 & Obat dan Makanan untuk dilakukan pengujian labor. \\
\hline & Cendol) & $\begin{array}{l}\text {-Tidak Mudah Lengket } \\
\text {-Tidak Rusak atau Busuk } \\
\text { Meski Disimpan } 3 \text { Hari } \\
\text { diluar lemari Pendingin } \\
\text {-Tercium Bau Menyengat } \\
\text {-Makanan Berwarna Merah } \\
\text { dan Lebih Mencolok }\end{array}$ & & & $\begin{array}{l}\text { Daftar Rujukan } \\
\text { [1] Darmayunata, Y. (2018). Sistem Pakar Berbasis Web } \\
\text { Menggunakan Metode Backward Chaining Untuk Menentukan } \\
\text { Nutrisi Yang Tepat Bagi Ibu Hamil. INTECOMS: Journal of } \\
\text { Information Technology and Computer Science, 1(2), 231-239. } \\
\text { DOI: https://doi.org/10.31539/intecoms.v1i2.302. }\end{array}$ \\
\hline \multirow[t]{2}{*}{2} & Mie & $\begin{array}{l}\text {-Bertekstur Kenyal } \\
\text {-Tidak Mudah Lengket } \\
\text {-Warna Kuning Mencolok } \\
\text {-Mi Berwarna Mengkilap, } \\
\text { Tidak Lengket, dan Tidak } \\
\text { Mudah Putus }\end{array}$ & Boraks & 1 & $\begin{array}{l}\text { [2] Kurniawan, A., Sumijan., \& Na'am, J. (2019). Sistem Pakar } \\
\text { Identifikasi Modalitas Belajar Siswa Menggunakan Metode } \\
\text { Forward Chaining. Jurnal RESTI (Rekayasa Sistem dan } \\
\text { Teknologi Informasi), } 3(3), \quad 518-523 . \\
\text { https://doi.org/10.29207/resti.v3i3.1166. }\end{array}$ \\
\hline & & $\begin{array}{l}\text {-Tidak Rusak atau Busuk } \\
\text { Meski Disimpan } 3 \text { Hari } \\
\text { diluar lemari Pendingin } \\
\text {-Beraroma Mencurigakan, } \\
\text { Binatang tidak mau } \\
\text { mendekat }\end{array}$ & & & $\begin{array}{l}\text { [3] Dian, R., Sumijan, S., \& Yunus, Y. (2020). Sistem Pakar dalam } \\
\text { Identifikasi Kerusakan Gigi Pada Anak dengan Menggunakan } \\
\text { Metode Forward Chaining dan Certainty Factor. Jurnal Sistim } \\
\text { Informasi dan Teknologi, 2(3), } 1-6 . \quad \text { DOI: } \\
\text { https://doi.org/10.37034/jsisfotek.v2i3.36. }\end{array}$ \\
\hline \multirow[t]{3}{*}{3} & Ikan & $\begin{array}{l}\text {-Tidak Rusak atau Busuk } \\
\text { Meski Disimpan } 15 \text { Hari }\end{array}$ & & & $\begin{array}{l}\text { [4] Fadel, A., Mardayulis, M., \& Yunita, P. (2018). Aplikasi Sistem } \\
\text { Pakar Pusat Informasi Konseling Remaja (PIK-R) Di SMAN } 2\end{array}$ \\
\hline & Tongkol & $\begin{array}{l}\text { didalam Lemari Pendingin } \\
\text {-Beraroma Mencurigakan, } \\
\text { Binatang tidak mau }\end{array}$ & Formalin & 1 & $\begin{array}{l}\text { Dumai dengan Metode Backward Chaining Menggunakan } \\
\text { Bahasa Pemograman PHP. Informatika, 10(2), 47-55. DOI: } \\
\text { http://dx.doi.org/10.36723/juri.v10i2.115. }\end{array}$ \\
\hline & & $\begin{array}{l}\text { mendekat } \\
\text {-Ikan Segar memiliki Warna } \\
\text { Insang Merah Tua } \\
\text {-Daging Berwarna Putih }\end{array}$ & & & $\begin{array}{l}\text { [5] Julita, R. (2018). Sistem Pakar Pemilihan Menu Makanan } \\
\text { Berdasarkan Penyakit dan Golongan Darah. Pseudocode, 5(1), } \\
\text { 56-67. DOI: https://doi.org/10.33369/pseudocode.5.1.56-67 . }\end{array}$ \\
\hline \multirow[t]{2}{*}{4} & $\begin{array}{l}\text { Ayam } \\
\text { Potong }\end{array}$ & $\begin{array}{l}\text { Pucat } \\
\text {-Tidak Rusak atau Busuk } \\
\text { Meski Disimpan } 15 \text { Hari } \\
\text { didalam Lemari Pendingin } \\
\text {-Tercium Bau Menyengat }\end{array}$ & Formalin & 1 & $\begin{array}{l}\text { [6] Nurmaesah, N., Tullah, R., \& Cahandi, C. (2020). Sistem Pakar } \\
\text { Diagnosa Terjadinya Waste Plastik Berbasis Web dengan } \\
\text { Metode Backward Chaining. JURNAL SISFOTEK GLOBAL, } \\
\text { 10(1). DOI: https://doi.org/10.38101/sisfotek.v10i1.281. }\end{array}$ \\
\hline & & $\begin{array}{l}\text { Pada Makanan } \\
\text {-Ayam Bertekstur Padat dan } \\
\text { Lebih Keras Dibanding } \\
\text { Ayam Pada Umumnya } \\
\text {-Daging Berwarna Putih } \\
\text { Pucat }\end{array}$ & & & $\begin{array}{l}\text { [7] Dewi, S. V., \& Fauziah, F. (2018). Perancangan Aplikasi Sistem } \\
\text { Pakar Untuk Mendeteksi Penyakit Berdasarkan Golongan Darah } \\
\text { Berbasis Android Menggunakan Metode Backward Chaining. } \\
\text { Journal of Informatics And Computer Science, 4(2), 183-188. } \\
\text { DOI: https://doi.org/10.33143/jics.Vol4.Iss2.544. }\end{array}$ \\
\hline 5 & Kerupuk & $\begin{array}{l}\text {-Berwarna Mencolok } \\
\text { Jurnal Sistin }\end{array}$ & $\begin{array}{l}\text { Rodamin } \\
\text { Informas }\end{array}$ & Lan 1 & nologi Vol.3 No. 1 (2021) 34-40 \\
\hline
\end{tabular}

-Warna Tidak Merata, B

Terlihat Gumpalan Warna

Pada Makanan

-Makanan Terasa Lebih

Pahit

-Meninggalkan Bekas Warna

$\begin{array}{ll}\text { Agar - } & \text {-Warna Tidak Merata, } \\ \text { agar Es } & \text { Terlihat Gumpalan Warna }\end{array}$

Campur

Pada Makanan

Metanil

-Setelah Dimakan Terasa

Yellow

Gatal Di Tenggorokan

-Warna Kuning Mencolok

-Meninggalkan Bekas Warna

\section{Kesimpulan}

Pada Sistem Pakar identifikasi senyawa kimia boraks, formalin, rodamin $\mathrm{b}$ dan metanil yellow pada makanan menggunakan Metode Backward Chaining terdapat 18 ciri fisik makanan yang didapatkan dari pakar dan terdapat 6 buah data yang dilakukan pencarian dengan sistem menggunakan Metode Backward Chaining dan dibandingkan dengan data asli yang didapatkan dari pakar, didapatlah hasil kecocokan data dari pakar dengan hasil pencarian tersebut mendapatkan persentase $100 \%$. Solusi yang dihasilkan yaitu sampel tersebut harus dilakukan pengujian labor. Diharapkan aplikasi ini dapat membantu masyarakat dalam edukasi enyawa kima pada makanan dan mengidentifikasi tahap awal makanan sebelum dilaporkan ke Pengawas Obat dan Makanan untuk dilakukan pengujian labor.

Mengounakan Metode Backward Chaining Untuk Menentukan Nutrisi Yang Tepat Bagi Ibu Hamil. INTECOMS: Journal of Information Technology and Computer Science, 1(2), 231-239.

Identifikasi Modalitas Belajar Siswa Menggunakan Metode Forward Chaining. Jurnal RESTI (Rekayasa Sistem dan Teknologi Informasi), 3(3), 518-523. DOI:

Dian, R., Sumijan, S., \& Yunus, Y. (2020). Sistem Pakar dalam Informasi dan Teknologi, 2(3), 1-6. DOI: //doi.org/10.37034/jsisfotek.v2i3.36 Pakar Pusat Informasi Konseling Remaja (PIK-R) Di SMAN 2 Chaining Menggunakan Bahasa Pemograman PHP. Informatika, 10(2), 47-55. DOI: Julita, R. (2018). Sistem Pakar Pemilihan Menu Makanan Berdasarkan Penyakit dan Golongan Darah. Pseudocode, 5(1), Diagnosa Terjadinya Waste Plastik Berbasis Web dengan Metode Backward Chaining, JURNAL SISFOTEK GLOBAL

Dewi, S. V., \& Fauziah, F. (2018). Perancangan Aplikasi Sistem Pakar Untuk Mendeteksi Penyakit Berdasarkan Golongan Darah Journal of Informatics And Computer Science, 4(2), 183-188. DOI: https://doi.org/10.33143/jics.Vol4.Iss2.544 . 
[8] Herliana, A., Setiawan, V. A., \& Prasetio, R. T. (2018). Penerapan Inferensi Backward Chaining Pada Sistem Pakar Diagnosa Awal Penyakit Tulang. Jurnal Informatika, 5(1), 50-

[9] Sapri, S., \& Khairil, K. (2019). Sistem Pakar Penanganan Kasus Sengketa Tanah Menggunakan Metode Backward Chaining.
Jurnal

Teknik,

$17(2)$,

$113-124$

DOI:

10] Pranata, F. S., Na'am, J., \& Sumijan. (2019). Sistem Pakar Diagnosis Penyakit Jamur pada Manusia Menggunakan Input Suara Berbasis Android. Jurnal RESTI (Rekayasa Sistem dan Teknologi Informasi), 3(3), 435-442. DOI: https://doi.org/10.29207/resti.v3i3.1187 